Chronic Obstructive Pulmonary Diseases: Journal of the COPD Foundation

\title{
Editorial
}

\section{Long-Term Noninvasive Ventilation in COPD: Is High-Intensity NIV The Way To Go?}

\author{
Marieke L. Duiverman, $\mathrm{MD}, \mathrm{PhD}^{1}$ Peter J. Wijkstra, $\mathrm{MD}, \mathrm{PhD}^{1}$
}

\begin{abstract}
Abbreviations: chronic obstructive pulmonary disease, COPD; chronic hypercapnic respiratory failure, CHRF; noninvasive ventilation, NIV; inspiratory positive airway pressure, IPAP; breathing frequencies, BF; health-related quality of life, HRQoL; partial arterial carbon dioxide pressure, $\mathrm{PACO}_{2}$

Citation: Duiverman ML, Wijkstra PJ. Editorial. Long-term noninvasive ventilation in COPD: is high-intensity NIV the way to go? Chronic Obstr Pulm Dis (Miami). 2016;3(1):378-381. doi: http://dx.doi.org/10.15326/jcopdf.2015.3.0179
\end{abstract}

1 Department of Pulmonary Diseases, University Medical Center Groningen, University of Groningen, the Netherlands

\section{Address correspondence to:}

\section{M.L.Duiverman, MD, PhD}

University Medical Center Groningen

P.O.Box 30.001

9700 RB Groningen

The Netherlands

Phone: +31503613200

E-mail: m.l.duiverman@umcg.nl

\section{Keywords:}

chronic obstructive pulmonary disease; chronic respiratory failure; noninvasive ventilation

\section{Introduction}

Chronic obstructive pulmonary disease (COPD) is a chronic disease with high mortality and morbidity worldwide. Patients with end-stage COPD frequently develop chronic hypercapnic respiratory failure (CHRF) associated with end-of-life. In that stage of disease, treatment options are limited.

Long-term nocturnal noninvasive ventilation (NIV) has been applied in patients with chronic alveolar hypoventilation for decades. While there is no doubt that applying chronic nocturnal NIV improves outcomes in patients with restrictive and neuromuscular diseases, ${ }^{1}$ in COPD patients, only recently has evidence showing benefits of long-term NIV become available. ${ }^{2-4}$ However, despite these positive findings, the application of long-term NIV in patients with severe COPD should be carefully considered, as knowledge gaps exist with regard to patient selection, the optimal setting to initiate NIV, and the optimal ventilatory settings to be used.

In the October issue of the Chronic Obstructive Pulmonary Diseases: Journal of the COPD Foundation, Weir and colleagues again show that high-intensity nocturnal NIV can indeed improve daytime gas exchange in COPD patients with CHRF. ${ }^{5}$ Interestingly, they aimed to use very high inspiratory pressures (as they describe: the inspiratory positive airway pressure [IPAP] was titrated from a minimum of $20 \mathrm{~cm} \mathrm{H}_{2} \mathrm{O}$ up to the maximum IPAP tolerated with a maximum of $30 \mathrm{~cm} \mathrm{H} \mathrm{H}_{2} \mathrm{O}$; backup breathing frequencies [BF] set on the ventilator were gradually increased beyond the spontaneous BF to $18-22$ breaths/minute). This resulted in a mean IPAP of $27.3 \pm 4.7 \mathrm{~cm} \mathrm{H}_{2} \mathrm{O}$ and a mean backup BF of $15.4 \pm 2.9$ breaths/min. Despite the fact that the authors spent a huge amount of effort to increase compliance with the ventilator after hospital discharge, with daily telephone calls the first 4 days, and weekly telephone calls thereafter, compliance was disappointingly low. Two patients dropped out and only 5 of 9 patients had an adherence of at least 4 hours use per night on 5 out of 7 nights per week. Furthermore, 4 of 9 patients had a COPD exacerbation during the follow up period. This disappointing compliance, relatively high drop-out rates and high exacerbation rates might explain why only limited-to-no additional improvements in health-related quality of life (HRQoL) 
and lung function were found. Nevertheless, the paper does nicely address some important discussion points regarding long-term NIV in stable COPD.

First, we have learned that chronic NIV does not provide benefit in every COPD patient with CHRF. Unfortunately, we are insufficiently informed about the factors predicting a favourable response. Studies have shown us a few aspects that are important to recognize in selecting the appropriate patients. Patients with more severe CHRF seem to benefit more. ${ }^{6}$ Furthermore, benefit will only be achieved if patients truly suffer from prolonged CHRF. Chronic NIV will not improve outcomes once it is initiated in every patient who remains hypercapnic after an exacerbation as a large part of these patients will recover to normocapnia spontaneously and thus, do not need chronic NIV. ${ }^{7}$ Weir et al choose to include patients once $>14$ days post-hospital discharge. Upcoming trials hopefully will provide more insight in this optimal timing issue.

Secondly, the setting in which NIV is applied needs to be discussed. We have shown important benefits of adding nocturnal NIV to pulmonary rehabilitation in terms of improvement in HRQoL, exercise tolerance and lung function. ${ }^{2,3} \mathrm{We}$ believe that, in carefully selected patients, the combination of nocturnal NIV with pulmonary rehabilitation provides the optimal package of treatment. An additional advantage might be that a setting is created in which close contact between the patient and caregivers is established, which, as recognized by Weir et al, may be crucial for a successful NIV initiation and compliance at long-term.

Finally, benefits of chronic NIV seem to be dependent on the ventilatory settings used. High-intensity NIV in patients with stable COPD was reported first by Windisch et al. ${ }^{8}$ They showed, in an uncontrolled study in 14 COPD patients with severe CHRF (mean baseline partial arterial carbon dioxide pressure $\left[\mathrm{PaCO}_{2}\right] 59.5 \mathrm{mmHg}$ ), that NIV with a high mean IPAP of $29.8 \mathrm{~cm} \mathrm{H} 2 \mathrm{O}$, combined with a high backup BF of 22.9 breaths/min, could reduce $\mathrm{PaCO}_{2}$ from 59.5 to $46.0 \mathrm{mmHg}$ during spontaneous breathing at daytime. These data were confirmed in their own cohort of patients ventilated with high-intensity NIV in a retrospective analysis published 3 years later. In this study it was shown that with a mean IPAP of 27.7 $\mathrm{cm} \mathrm{H}_{2} \mathrm{O}$ and a BF of 20.8 breaths/min a reduction in daytime $\mathrm{PaCO}_{2}$ of $6.9 \mathrm{~mm} \mathrm{Hg}$ and an improvement in lung function could be achieved after 2 months. ${ }^{9}$ However, these data were uncontrolled. In 2011, Dreher et al published the results of a randomized cross-over trial, showing that high-intensity NIV was indeed more effective compared to low-intensity NIV, each applied for 6 weeks. ${ }^{10}$ However, the patient number was small (14 patients) and only medium-term effects ( 6 weeks) of each mode were tested. Consequent randomized controlled trials confirmed these results and have shown that with nocturnal NIV with settings aimed at really improving ventilation (reaching normocapnia at daytime), improvement in HRQoL, lung function, and even survival can be achieved. ${ }^{2-4}$

Despite these promising findings of high-intensity NIV, important points remain to be discussed. First, survival benefit of high-intensity NIV as compared to standard care has been shown in only one, although large and well designed, randomized controlled trial. ${ }^{4}$ The survival benefit found in this study is, however, difficult to compare with the other long-term trials as the mortality was relatively high in the control group. Nevertheless, we believe it will, at least in our country (the Netherlands), raise ethical concerns to perform another large randomized controlled trial comparing NIV with standard care in patients with CHRF once such a large survival benefit has been shown in a group of patients for whom treatment options are limited. Secondly, although with high-intensity NIV, true benefits of chronic NIV in stable COPD were shown for the first time, we lack knowledge about what the optimal setting should be, what the true mechanisms leading to benefits of this mode of ventilation are and what disadvantages can be expected. Is it really the main aim to improve $\mathrm{PaCO}_{2}$ or is the improvement in $\mathrm{PaCO}_{2}$ an expression of another underlying mechanism being more important for improvement in HRQoL and survival? Should we focus only on this $\mathrm{PaCO}_{2}$ or include other parameters too when initiating NIV? Currently, as we are incompletely informed about the mechanism of why long-term NIV improves long-term patient-related outcomes it is difficult to answer this question.

Some additional notes can be made regarding the ventilatory settings. High-intensity NIV is defined as a specific ventilator setting aimed at achieving normocapnia or the lowest $\mathrm{PaCO}_{2}$ values as possible. ${ }^{11}$ This implies that is it not the IPAP and/or BF that should be set at certain levels, but that for each individual patient the setting should be examined with which maximal improvement in gas exchange is achieved. Furthermore, it is questionable whether both high-pressures and highfrequencies are necessary. In a short-term cross-over 
trial Murphy et al showed that a setting with only high IPAP is as good as a setting with high IPAP and high backup BF. ${ }^{12}$ Furthermore, the number of hours use per day could be at least as important as the pressures and frequencies used. However, compliance might be a problem when (too) high-intensity settings are used. Finally, the drawbacks of high-intensity NIV are not completely clear yet. It was shown that high-intensity NIV might reduce cardiac output, ${ }^{13}$ and that it might increase patient-ventilator asynchrony. Unfortunately, data on these potential disadvantages are limited or not there at all.

The data of Weir et al, although uncontrolled, nicely draws our attention again to the potential benefits but also pitfalls and potential factors limiting benefits of high-intensity NIV. Future research will be needed to unravel these issues and optimize the treatment with long-term NIV of the increasing number of stable hypercapnic COPD patients with CHRF. 


\section{References}

1. Simonds AK, Elliott MW. Outcome of domiciliary nasal intermittent positive pressure ventilation in restrictive and obstructive disorders. Thorax.1995;50:604-609. doi: http://dx.doi.org/10.1136/thx.50.6.604

2. Duiverman ML, Wempe JB, Bladder G, et al. Two-year homebased nocturnal noninvasive ventilation added to rehabilitation in chronic obstructive pulmonary disease patients: a randomized controlled trial. Respir Res. 2011;12:112-120. doi: http://dx.doi.org/10.1186/1465-9921-12-112

3. Duiverman ML, Wempe JB, Bladder G, et al. Nocturnal noninvasive ventilation in addition to rehabilitation in hypercapnic patients with COPD. Thorax. 2008;63(12):1052-1057. doi: http://dx.doi.org/10.1136/thx.2008.099044

4. Köhnlein T, Windisch W, Köhler D, et al. Non-invasive positive pressure ventilation for the treatment of severe stable chronic obstructive pulmonary disease: a prospective, multicentre, randomised, controlled clinical trial. Lancet Respir Med. 2014;2(9):698-705.

doi: http://dx.doi.org/10.1016/S2213-2600(14)70153-5

5. Weir M, Marchetti N, Czysz A, et al. High intensity non-invasive positive pressure ventilation for stable hypercapnic chronic obstructive pulmonary disease patients. Chronic Obstr Pulm Dis (Miami). 2015; 2(4): 313-320.

doi: http://dx.doi.org/10.15326/jcopdf.2.4.2015.0145

6. Struik FM, Lacasse Y, Goldstein RS, Kerstjens HA, Wijkstra PJ. Nocturnal noninvasive positive pressure ventilation in stable COPD: a systematic review and individual patient data metaanalysis. Respir Med. 2014;108(2):329-337. doi: http://dx.doi.org/10.1016/j.rmed.2013.10.007

7. Struik FM, Sprooten RT, Kerstjens HA, et al. Nocturnal non-invasive ventilation in COPD patients with prolonged hypercapnia after ventilatory support for acute respiratory failure: a randomised, controlled, parallel-group study. Thorax.2014;69(9):826-834. doi: http://dx.doi.org/10.1136/thoraxjnl-2014-205126

8. Windisch W, Vogel M, Sorichter S, et al. Normocapnia during nIPPV in chronic hypercapnic COPD reduces subsequent spontaneous $\mathrm{PaCO}_{2}$. Respir Med. 2002;96(8):572-579. doi: http://dx.doi.org/10.1053/rmed.2002.1326

9. Windisch W, Kostic S, Dreher M, et al. Outcome of patients with stable COPD receiving controlled noninvasive positive pressure ventilation aimed at a maximal reduction of $\mathrm{PaCO}_{2}$. Chest. 2005;128(2):657-662. doi: http://dx.doi.org/10.1378/chest.128.2.657

10. Dreher M, Storre H, Schmoor C, Windisch W. High-intensity versus low-intensity noninvasive ventilation in stable hypercapnic COPD patients: A randomized cross-over trial. Thorax. 2010;65(4):303-308. doi: http://dx.doi.org/10.1136/thx.2009.124263

11. Windisch W, Storre J, Kohnlein T. Nocturnal non-invasive positive pressure ventilation for COPD. Expert Rev Respir Med. 2015;9(3):295-308.

doi: http://dx.doi.org/10.1586/17476348.2015.1035260
12. Murphy PB, Brignall K, Moxham J, Polkey MI, Davidson AC, Hart N. High pressure versus high intensity noninvasive ventilation in stable hypercapnic chronic obstructive pulmonary disease: a randomized crossover trial. Int J Chron Obstruct Pulmon Dis. 2012;7:811-818. doi: http://dx.doi.org/10.2147/COPD.S36151

13. Lukácsovits J, Carlucci A, Hill N, et al.Physiological changes during low- and high-intensity noninvasive ventilation. Eur Respir J. 2012; 39(4):869-875. doi: http://dx.doi.org/10.1183/09031936.00056111 